MODERN CELESTIAL MECHANICS:

FROM THEORY TO APPLICATIONS 


\section{Modern Celestial Mechanics: From Theory to Applications}

Proceedings of the Third Meeting on Celestical Mechanics - CELMEC III, held in Rome, Italy, 18-22 June, 2001

\section{Edited by}

A. CELletTI

Dipartimento di Matematica,

Università di Roma "Tor Vergata", Italy

\section{S. FERRAZ-MELLO}

Instituto de Astronomia, Geofísica e Ciências Atmosféricas, Universidade de São Paulo, Brazil

and

\section{J. HENRARD}

Département de Mathématique, FNDP, Namur, Belgium

Partly reprinted from Celestial Mechanics and Dynamical Astronomy Volume 83: 1-4 (2002) 
A C.I.P. Catalogue record for this book is available from the Library of Congress.

ISBN 978-90-481-6078-5 ISBN 978-94-017-2304-6 (eBook)

DOI 10.1007/978-94-017-2304-6

Printed on acid-free paper

Front cover graphics by Ettore Perozzi

All Rights Reserved

(C) 2002 Springer Science+Business Media Dordrecht

Originally published by Kluwer Academic Publishers in 2002

Softcover reprint of the hardcover 1st edition 2002

No part of this work may be reproduced, stored in a retrieval system, or transmitted

in any form or by any means, electronic, mechanical, photocopying, microfilming, recording or otherwise, without written permission from the Publisher, with the exception of any material supplied specifically for the purpose of being entered and executed on a computer system, for exclusive use by the purchaser of the work. 


\section{CONTENTS}

Preface

\section{Space Dynamics and Applications}

A. Albertella, F. MiGLiACCIO and F. SANSÓ / GOCE: The Earth Gravity Field by Space Gradiometry

C. BONANNO and A. MILANI / Symmetries and Rank Deficiency in the Orbit Determination Around Another Planet

R. GREENBERG, G. V. HOPPA, P. GEISSLER, A. SARID and B. R. TUFTS / The Rotation of Europa

E. PEROZZI, L. CASALINO, G. COLASURDO, A. ROSSI and G. B. VALSECCHI / Resonant Fly-By Missions to Near Earth Asteroids

G. B. VALSECCHI and A. ROSSI / Analysis of the Space Debris Impacts Risk on the International Space Station

\section{Solar and Extrasolar Systems}

R. DVORAK and Á. SÜLI / On the Stability of the Terrestrial Planets as Models for Exosolar Planetary Systems

G. F. GRONCHI / Generalized Averaging Principle and the Secular Evolution of Planet Crossing Orbits

M. GUZZO, Z. KNEŽEVIĆ and A. MILANI / Probing the Nekhoroshev Stability of Asteroids

J. D. HADJIDEMETRIOU / Resonant Periodic Motion and the Stability of Extrasolar Planetary Systems

D. J. SCHEERES / Stability in the Full Two-Body Problem

\section{Chaos and Order}

G. CIRAOLO and M. PETTINI / Geometry of Chaos in Models of Stellar Dynamics

G. CONTOPOULOS, N. VOGLIS and C. KALAPOTHARAKOS / Order and Chaos in Self-Consistent Galactic Models

M. FOUCHARD, E. LEGA, CH. FROESCHLÉ and C. FROESCHLÉ / On the Relationship Between Fast Lyapunov Indicator and Periodic Orbits for Continuous Flows 


\section{Periodic Orbits and Resonance}

L. BIASCO and L. CHIERCHIA / Effective Hamiltonian for the D'Alembert Planetary Model Near a Spin/Orbit Resonance

A. CELLETTI, A. CHESSA, J. HADJIDEMETRIOU and G. B. VALSECCHI / A Systematic Study of the Stability of Symmetric Periodic Orbits in the Planar, Circular, Restricted Three-body Problem

A. CELLETTI, G. DELLA PENNA and C. FROESCHLÉ / Estimate of the Transition Value of Librational Invariant Curves

S. FERRAZ-MELLO / Ideal Resonance Problem: The Post-PostPendulum Approximation

J. HENRARD / The Web of Periodic Orbits at $L_{4}$

\section{Numerical and Analytical Methods}

M. GUZZO / Long-term Stability Analysis of Quasi Integrable Degenerate Systems Through the Spectral Formulation of the Nekhoroshev Theorem

C. MARCHAL / How the Method of Minimization of Action Avoids Singularities

H. YOSHIDA / Non-existence of the Modified First Integral by Symplectic Integration Methods II: Kepler Problem

\section{Short Papers}

V. CARRUBA, J. A. BURNS, W. BOTTKE and D. NESVORNÝ / Dynamical Evolution of the Adeona and Gefion Asteroid Families

S. CASOTTO / On the Expansion of the External Gravitational Potential in Spheroidal Harmonics

A. CELLETTI and C. FALCOLINI / Periodic Orbits Approximation of Analyticity Domains of Invariant Curves

$\mathrm{CH}$. CIRCI and P. TEOFILATTO / Low $\Delta V$ Orbit Insertion in Interplanetary Missions

CH. FROESCHLÉ, P. MICHEL, R. GONCZI, T. J. JOPEK, G. LONGO and L. FOSCHINI / Long-Term Dynamics of the Tunguska Cosmic Body

F. GABERN and Á. JORBA / On the Triangular Points of the SunJupiter System 
D. GAUCHEZ, M. FOUCHARD and J. SOUCHAY / Inter-Comparisons Between Numerical Integrations and Analytical Theory for the Solar System

G. GÓMEZ and J. M. MONDELO / The Central Manifold for the Collinear Libration Points

TH. A. KOTOULAS and J. D. HADJIDEMETRIOU / Periodic Orbits of Trans-Neptunian Objects at the 2/3 and 3/4 Resonances

V. LAINEY and A. VIENNE / Rotation of Natural Shaped Satellites and their Orbital Motion

407

U. LOCATELLI and A. GIORGILLI / From Kolmogorov's Normalization Algorithm to the Orbits in the Three-Body Planetary Problem

F. LOPEZ-GARCIA and A. BRUNINI / Dynamical Behaviour of Asteroids in the Region $a<2 \mathrm{AU}$

M. OLLÉ, J. R. PACHA and J. VILLANUEVA / Study of the Hamiltonian Form Near a Resonant Periodic Orbit

E. PEROZZI / Asteroid (9934) Caccioppoli: What's in a Name?

E. PILAT-LOHINGER, R. DVORAK and B. FUNK / A Stability Study of S-type Orbits in the Binary Gliese 86

G. PUCACCO and K. ROSQUIST / Non-Integrability Tests of Weakly Integrable Systems

P. ROBUTEL / Application of the Frequency Map Analysis to the Global Dynamics in the Solar System

CH. SKOKOS / Realistic Estimations of the Effective Stability Region of the Trojan Asteroids

K. TSIGANIS, H. VARVOGLIS and A. ANASTASIADIS / Diffusion of Asteroids in Mean Motion Resonances

F. VACHIER / Orbital Behaviour of the Inner Faint Jovian Satellites: Modelling the Motion of JXIV Thebe

H. VARVOGLIS, K. TSIGANIS and J. D. HADJIDEMETRIOU/Stable Chaos in Mean Motion Resonances

A. VIENNE / Tethys' Eccentricity from the Observations of Mimas: A Way to Understand the Evolution of the Mimas-Tethys System

D. VOKROUHLICKÝ and M. BROŽ / Interaction of the Yarkovsky-Drifting Orbits with Weak Resonances: Numerical Evidence and Challenges 


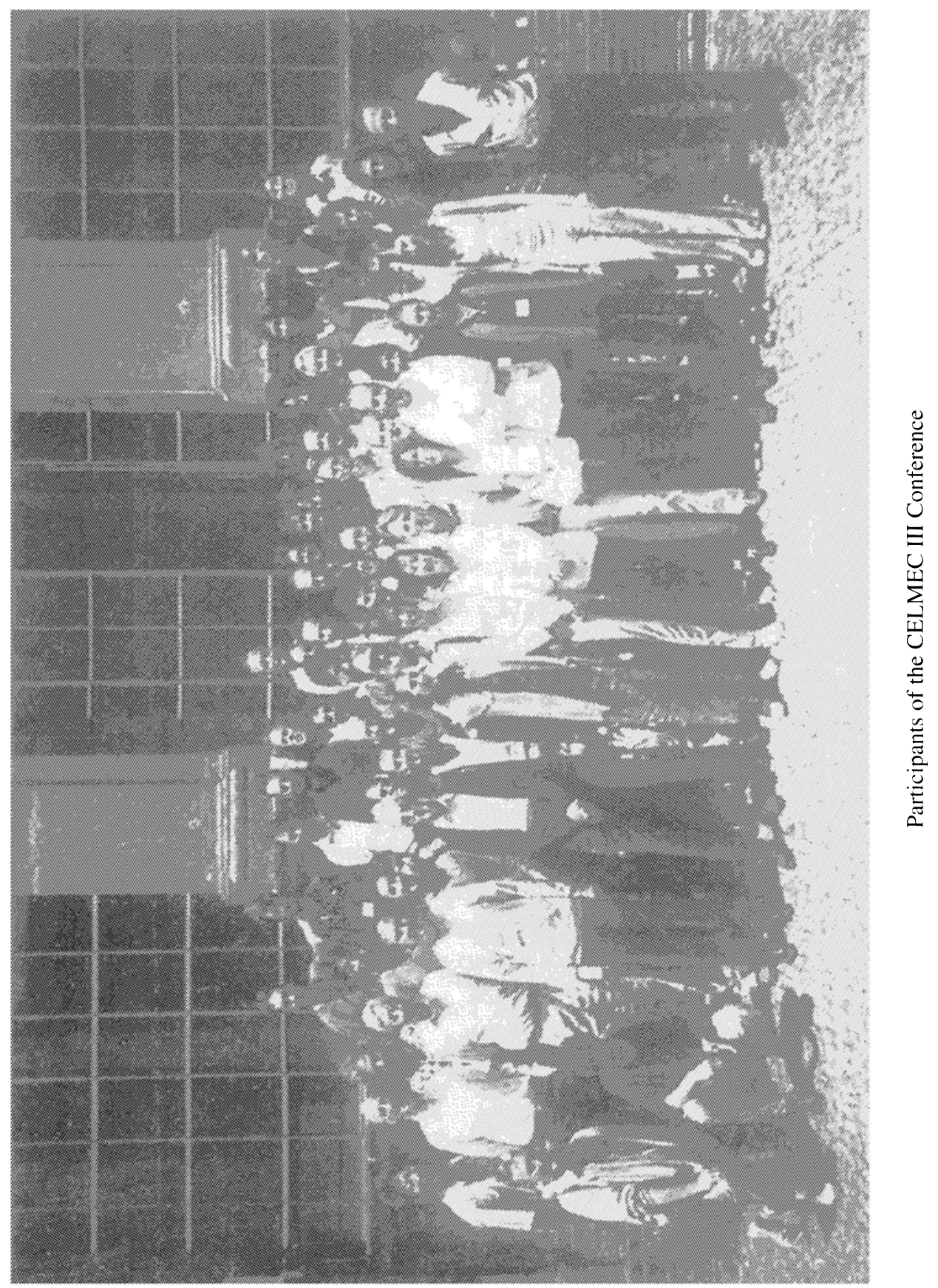




\section{PREFACE}

At the opening of the "Third Meeting on Celestial Mechanics - CELMEC III", strong sensations hit our minds. The conference (18-22 June 2001) was being held in Villa Mondragone, a beautiful complex of buildings and gardens located within the township of Monte Porzio Catone, on the hills surrounding Rome. A former papal residence, the building has been recently restored by the University of Rome "Tor Vergata" to host academic activities and events. The conference room is called "Salone degli Svizzeri": here, Gregory XIII, on February 24, 1582, gave its sanction to the reform of the Julian calendar and declared officially in use the calendar still adopted nowadays. The magnificent high walls and tall ceiling strongly resounded, giving to our voice a peculiar Vatican sound, which took us by surprise. May be - we thought - a distant echo of the very words of Gregory XIII proclaiming the modern calendar was still haunting the room.

Around us, in the audience, many countries were represented, thus indicating that the idea of putting together the three "souls" of modern Celestial Mechanics - perturbation theories, solar and stellar system studies, spaceflight dynamics had been successful. CELMEC III is in fact the latest of a series of meetings (the first two editions took place in 1993 and 1997 in L'Aquila, Italy) whose aim is to establish a common ground among people working in Celestial Mechanics, yet belonging to different institutions such as universities, astronomical observatories, research institutes, space agencies and industries.

The meeting has been dedicated to Paolo Farinella and, in the opening lecture, a passionate portrait of him was given by Andrea Milani. To those who had the chance of knowing Paolo as a friend and as a colleague, it still hurts that he had to leave our planet so soon. Yet, his human qualities and the incredible amount of good science he was able to carry out in his lifetime clearly appeared, making us feel lucky that Paolo has been living on our planet.

Finally, we note an amusing coincidence. The roman football team had just won the Italian championship and we felt that we could share the happiness and the joyful attitude of the people around us. After all, both celestial mechanics and football are dealing, basically, with the same problem: handling stiff trajectories in space.

The CELMEC III organizing committee composed by Alessandra Celletti (University of Rome "Tor Vergata"), Andrea Milani (University of Pisa), Ettore Perozzi (Telespazio, Rome) and Giovanni B. Valsecchi (Institute for Space Astrophysics and Cosmic Physics, CNR, Rome) wishes to thank all participants for their enthusiasm in keeping the discussion alive. Many institutions have supported the meeting. To the University of Rome "Tor Vergata" we acknowledge kind hospitality and funding. The township of Monte Porzio Catone provided an essential aid in solving many logistic problems and a widely appreciated visit to the local wine museum, while the Observatory of Rome at Monte Porzio Catone offered a 
pleasant music concert. The Gruppo Nazionale per la Fisica Matematica (GNFM) and Telespazio had provided a continuing financial support, which dates back to the first CELMEC. The meeting was also sponsored by the Department of Mathematics of the University of Rome "Tor Vergata", the University of Pisa, the CNR Institute for Space Astrophysics and Cosmic Physics, the European Space Agency (ESA) and the Italian Space Agency (ASI). All of them have also greatly helped us in keeping the meeting open to the new generations of scientists by means of grants to your participants. Th publication of this book has been made possible thanks to the support of the Office of the Italian National Research Council (CNR) President.

Alessandra Celletti Sylvio Ferraz-Mello Jacques Henrard Ettore Perozzi 